\title{
The Analysis and Fast Appraisal of Shale Gas Exploration Risk in China
}

\author{
Geng Xiaojin* \\ school of Management \\ China University of Mining \& Technology \\ Beijing, China \\ e-mail:654933375@qq.com \\ * Corresponding Author \\ Wu Yanting \\ school of Geoscience and Surveying Engineering \\ China University of Mining \& Technology \\ Beijing, China
}

\author{
You Shenggang \\ school of Geoscience and Surveying Engineering \\ China University of Mining \& Technology \\ Beijing, China
}

\begin{abstract}
- the exploration risk is the most important factor that hamper the development of shale gas industry now. So in this paper we try to analysis and appraisal the exploration risk in order to help the investors to make investment decision. Through analysis we know that there are two kinds of risks: one is distribution risk; the other is cognitive risk. Then a probability model is established to fast appraisal the exploration risk. The formula of the model shows that the generation condition is the most important factor, the thickness of the shale, the content of organic, the thermal maturity of organic, the condition of the roof and floor layer, the fault condition, exposed or not, the buried depth of the reservoir are the key factors, the content of brittle mineral and the volume percentage of "wet" rock are the "plus" term in the model, not the decisive factors.
\end{abstract}

Keywords-shale gas; exploration risk; key factor; probability model

\section{INTRODUCTION}

China is a large country in the critical time of industrialization and urbanization. Under the condition of energy demand continuous increasing, to protect the energy supply and deal with the international pressure of the climate change has become an important task of China's energy industry. Shale gas is a kind of unconventional natural gas resource with relative clean property in primary energy resources. Therefore to promoting the development of shale gas industry is quite significant for china to guarantee the energy supply, to reduce carbon dioxide emission, to deal with the international pressure of climate change. However the shale gas industry in China is still at its early stage, the shale gas accumulation and enrichment is still not fully understood, so the exploration is full of risk and the prospect of this industry is full of doubt. On this condition, in this paper we try to analysis the exploration risk and established a probability model to fast appraisal the risk and in order to help investors make decision.

\section{THE ANALYSIS OF SHALE GAS EXPLORATION RISK}

We start to research on shale gas in China since 2000, and oil companied began to make substantial exploration in 2009 [1]. In 2014, Sinopec made a breakthrough in Fuling shale gas exploration field, means that shale gas industry enter into commercial development in China [2]. Research findings about the accumulation and enrichment of shale gas reservoir provide us many important reference materials. These findings make the scholars to realize that the conservation condition is important factors for the shale gas reservoir, so they put the conservation condition together with the generation and storage conditions to be the key conditions for the reservoir formation [3,4]. However, there are some distribution characteristics of these factors in strata. The regulation of these distribution characteristics and the difficult of the investigation of these characters is one of the mainly influence factors of the exploration risk, we called geological distribution risk. The second exploration risk is cognition risk. Shale gas is a kind of natural resource that buried in the underground layers of thousands kilometer depth. The exploration can only conduct by investigation of some indexes and infer from experience, but China's shale gas exploration is just in the early stage, the law of shale gas reservoir formation has not yet fully understood, so the exploration is fully of risk.

For geological distribution risk, if the distribution have rule and the distribution can be investigated simply, this distribution risk is low, vice versa. For cognition risk, if the influence of the factor is clear, the cognition risk is low, conversely the cognition risk is high.

\section{A. The generation risk analysis}

The factors that influence shale gas generation include the thickness of high quality shale, the organic content of the shale, the thermal maturity of organic. These factors is in the same layer so that they are deposited in the same environment, thus the uncertainly of these factors in the same layer is relatively low, the exploration risk is low accordingly. But the exploration risk for the strange layer 
will be high because the generation law is still not fully understood at present. According to American experience, theoretically there is gas generated during the whole process of important and all source rocks that entered into the "gas window" can generate shale gas to form reservoir [5-7]. but some scholars believe that there is an enrichment zone which is accumulated by a short migration of shale gas [8]. So whether the shale gas reservoir is formed by the short migration or all shale layer can form reservoir is disputed. For example, some scholars argue about the limitation of the lowest content of organic, some deem that the limitation is $1.0 \%$, some proposed it should be greater than $2.0 \%$, others suggest it better to be more than $2.5 \%$ $[9,10]$, and so on. There are many problems like that can't be determined, there is full of the cognition risk about generation.

\section{B. The storage risk analysis}

The storage condition is connected to the generation in some extent. A lot of researches have show that shale gas are mainly stored in micro pores and micro cracks. The micro pores were formed in the process of organic matters to be maturated [11]. The micro cracks were formed by the gas generation which caused the rock rupture to form micro cracks when the surrounding pressure increase [4]. So the storage condition of shale gas is highly related to its generation, that is the more of the shale gas was generated, the better of the storage condition. In addition, the content of brittle minerals can also affect the formation of the micro cracks [12]. In the shale the brittle minerals mainly indicate the quartz, the content of which is mainly affected by the buried environment which can be ascertained by geologic investigation. So the uncertainty is relatively less, the exploration risk is low correspondingly. The dry or wet of the rock have great influence on the enrichment of shale gas reservoir, moreover the dry or wet of the rock is not easy to ascertained at the early exploration, so the dry or wet of the rock is the main risk of the storage condition.

\section{The conservation risk analysis}

Since the success of the Fuling shale gas reservoir exploration, experts recognized that the conservation conditions are also the key factors that affect the formation of the reservoir. The conservation conditions should be included into the important influences of shale gas reservoir, if the conservation conditions had suffered any damage, the reservoir will destroy a lot. The factors that influence the conservation of shale gas reservoir include the condition of the roof and floor layers, the intensity of tectonic activities, the damage of the fault, the layer have been lift or not, have surface any erosion or not, and so on. In these factors, except for the condition of the roof and floor layer may not suddenly change, the other factors have great uncertainty for different place which means that these factors are not easy to determine by simple survey, so they are the mainly risk factors on conservation.

\section{PROBABILITY APPRAISAL MODEL}

According to the knowledge that the shale gas enrich and the analysis of the exploration risk, we know that the formation of the shale gas reservoir with commercial exploited value three conditions must be satisfied including the generation of shale gas, the rich of storage spaces, the closed conservation conditions. Therefore the probability model that we established uses a productive relation to explain their important influence to the formation of the shale gas reservoir. The hole formula is expressed that the probability of the shale gas reservoir formation $(\%)=$ the probability of shale gas generation $(\%)$ $\times$ the probability of shale gas storage $(\%) \times$ the probability of shale gas was well conserved $(\%)$. All the values of the probability are determined according to its subordinate factors, the concrete analysis is as follow.

\section{A. The appraisal of the generation condition}

The factors that influence the generation of shale gas include the thickness of high quality shale, the organic content of the shale, the thermal maturity of the organic matter. The influence of each factor to the generation is also be expressed with productive relationship. The appraisal of the generation condition are expressed as:

The probability of the generation $(\%)=$ the value of the thickness condition of high quality shale $(\%) \times$ the value of the organic content of shale $(\%) \times$ the value of the thermal maturity of the organic $(\%)$.

The probability value of each given factor in the above represent the probability of shale gas generation under the corresponding conditions.

The thickness of high quality shale. The thickness of the high quality shale in America five largest shale gas reservoirs and the core mining area in Canadian are more than $30 \mathrm{~m} \mathrm{[9].} \mathrm{In} \mathrm{Fuling} \mathrm{shale} \mathrm{gas} \mathrm{reservoir} \mathrm{the} \mathrm{value} \mathrm{is}$ between 35-45m [4]. Li Yanjun, et al., research out that in order to generate a large number of shale gas the thickness of the high quality shale (TOC $>2 \%$ ) should be greater than $15 \mathrm{~m}$. Curitis et al., deem that when the condition of the organic content and the thermal maturity is well satisfied, the minimum thickness of the high quality shale is $9 \mathrm{~m}$ [13]. Therefore, with a comprehensive of these researches, we propose that the value of the thickness of the high quality shale as follow: (1)when the thickness of the high quality shale is less than $9 \mathrm{~m}$, the probability value should be $0 \%$; (2) when the thickness of the high quality shale is between $9-15 \mathrm{~m}$, the probability value is suggested to be $50 \%$; (3)when the thickness of the high quality shale is between $15-30 \mathrm{~m}$, the probability value is suggested to be $80 \%$; (4) when the thickness of the high quality shale is more than $30 \mathrm{~m}$, the probability value can be $100 \%$.

The content of "TOC". Curitis et al., have proposed that the content of TOC should be more than $1.0 \%$, typically should be more than $2.0 \%$, it is better to be $2.5 \%$ $3.0 \%$ or even more [13]. American oil corporation generally ask the content of TOC in the effective shale to be more than 2.0\% [9]. Li Yanjun, et al., think the shale of the Longmaxi Group is over maturated, so according to the organic carbon recovery method, in order to achieve the original condition of the Barnett shale, the residual TOC content should reach to $1.0 \%$ [9]. According to the knowledge about the content of TOC, we suggest the probability value should be as follow: (1)when the content of TOC is more than $2.5 \%$, the probability value can be $100 \%$; (2) when the content of the TOC is between $1.0 \%$ $2.0 \%$, the probability value should be $60 \%$; (3) when the content of TOC is less than $1.0 \%$, the probability value should be $0 \%$. 
The thermal maturity of the organic. In theory, there are shale gas generation in the whole diagenetic process, but in fact only when the organic matters are entered into the "gas window" (Ro $>1.3 \%)$, the shale gas can be generated enough to form a commercial exploited reservoir. Burnaman et al. think that the Ro should be in 1.0\%-3.0\% for the reservoir formation. For the high depth buried shale, if the Ro is more than $3 \%$ the hydrocarbons will start to destroy. According to the relation graph between the Ro and the hydrocarbon generation process, the superior limit of the Ro for the shale gas of pyrogenic decomposition or spitting decomposition of organic is $3.0 \%$, and the preservation limit of the Ro for the dry gas is $4.6 \%$ [9]. The value of the thermal maturity of marine shale is suggested as follow: when Ro is between $1.3 \%-4.0 \%$, the probability value can be $100 \%$, and for the other conditions the probability value should be $0 \%$.

\section{B. The appraisal of the storage condition}

The storage condition of shale gas is mainly related to the generation condition, besides the brittle mineral content and the dry or wet condition of the rock is the other factors that influence the shale gas storage. In this paper, we divided the space of shale gas storage spaces into two kinds, the micro pore and the micro crack, and it is assumed that the micro crack and micro pore each account for $50 \%$ of the storage space. Moreover, the wet rock only affect the adsorbed gas. According to shale gas exploitation experience in America the adsorption gas account a proportion of $20 \%-80 \%$ [9]. Therefore we assumed that the influence of the wet rock is about $50 \%$. The probability value of the storage condition is as follow:

the probability of the storage condition $=$ (the probability value of the generation condition $\times 50 \%+$ the probability value of the brittle mineral condition $\times$ the probability value of the generation condition $\times 50 \%) \times(1$ $50 \% \times$ the volume percentage of the wet rock). In which "the probability value of the generation condition $\times 50 \%$ " represent the micro pores space and "the probability value of the brittle mineral condition $\times$ the probability value of the generation condition $\times 50 \%$ " represent the micro crack space, " $50 \% \times$ the volume percentage of the wet rock" represent the influence of the wet rock.

The content of the brittle mineral not only affect the development of the natural fractures to influence the storage space of shale gas, but also affect the fracturing production to influence the output of shale gas wells. In the commercial exploited shale gas reservoir in America the content of quartz is $35 \%-50 \%$, but in Canada the content of quartz is asked to be $40 \%$, at least to be $25 \%$ [9]. Therefore, the suggestion of the probability value is as follow: When the content of quartz is more than $50 \%$, the probability value can be $100 \%$; when the content of quartz is between $30-50 \%$, the probability value should be $80 \%$; when the content of the quartz is less than $30 \%$, the probability value should be $20 \%$.

\section{The appraisal of the conservation condition}

The conservation condition is critical for the formation of shale gas reservoir, because if the conservation condition is not well, the reservoir can be severe damage to disappear. The factors that influence the conservation conditions include the condition of the roof and floor layer, the condition of the fault, the lateral outlet of the shale layer, the erosion condition. In order to explain the important influence of each factor, the appraisal model is also expressed by productive relationship as follow:

the probability of the conservation condition $=$ the probability value of the condition of the roof and floor layer $\times$ the probability value of the tectonic condition $\times$ the probability value of the fault condition $\times$ the probability value of the lateral outlet condition $x$ the probability value of the erosion condition.

The suggestion of the probability value is as follow:

The roof and floor layer condition. If the roof and floor layers are low porosity and low permeability rock and are good seal up, haven't be erosion ever, haven't be broken by fault, the probability value should be $100 \%$; if any one of the roof or floor layer had been damaged, the probability value should be $0 \%$.

The condition of the tectonic activities. When it is in the anticline of the tectonic and the activities are relatively weak, the probability value should be $100 \%$; when the activities are intensive, the conservation layer is serve damaged, the probability value should be $50 \%$.

The condition of the fault. If there is no fault or the fault is fully closed, the probability value is suggested to be $100 \%$; if the fault is opened, the fault connected to the surface or the high permeability layer, the probability value should be $0 \%$.

The lateral outlet of the shale layer. The influence of the lateral outlet to the formation of shale gas is determined by the distance of the exploration site to where the shale layer are outlet, if the distance is long, the probability value should be $50 \%$, while the distance is short, the probability value should be $0 \%$.

The erosion condition. If the reservoir is buried in a properly depth(exceed 2000m [3]), haven't be erosion, the probability value should be $100 \%$; while the reservoir is buried is not enough depth or have exposed or sur-faced erosion, the probability value should be $0 \%$.

It seems that the probability value of the conservation conditions is much easy, but it is not the truth. At the early exploration, the factors that influence the conservation conditions are very difficult to judgment, it is very hard to determine the condition is "good" or "not good", so in finally to give a properly value of the above factors is also very difficult. Therefore in the early exploration the probability value of these factors can only be estimated by experiences of the experts. So the appraisal result get by a set of estimation will be deviated with the true value.

\section{The probability model of the exploration risk}

Coming up the above analysis, the appraisal model of the exploration risk is expressed as follow:

The probability of a shale gas reservoir $=$ the probability of the shale gas generation $\times$ the probability of the shale gas storage $\times$ the probability of the shale gas conservation $=$ (the probability value of the thickness of the high quality shale $x$ the probability value of the content of organic $x$ the probability value of the thermal maturity) $\times$ (the probability value of the shale gas generation $\times 50 \%$ + the probability value of the content of the brittle mineral $\times$ the probability value of the shale gas generation $\times 50 \%$ ) $\times(1-50 \% \times$ the volume percentage of the wet rock $) \times($ the probability value of the roof and floor layer condition $\times$ the probability value of the intensity of the tectonic activities $x$ 
the probability value of the fault condition $\times$ the probability value of the lateral outlet condition $\times$ the probability value of the erosion condition).

The formula show that the generation condition is squared, so its influence is serve important; the other factors such as the thickness of high quality shale, the content of organic, the thermal maturity of organic, the roof and floor layer condition, the fault condition, the lateral outlet, the buried depth, the erosion condition all have one condition at least to be valued zero, so they are the determined factor for shale gas reservoir; the last two factors that the content of brittle mineral and the volume percentage of wet rock are the plus term, means that they are the important factors but not the determine factors.

In addition, the probability model we established here is flexible, and the probability value of the above factors can be easily changed according to different understanding. Secondly, we are researched on the basis of the marine shale gas materials, while the continental shale gas reservoir may different, we haven't involved in this paper. Then we think the experience of the experts can help to exclude the cognition risk that mainly affect the generation, and the geologic materials can help to reduce the distribution risk, so we suggest to collect more materials related to hold the exploration risk. Last, we must know that any appraisal model can exclude the cognition risk and distribution risk, the probability appraisal model is not an exception, so the accuracy of this result is mainly on the further knowledge and geologic materials.

\section{CONCLUSION}

In this paper we analyzed the factors that influence the exploration risk to know that there are two kind of risks in generally: one is the distribution risk; the other is the cognition risk. On generation, the cognition risk is the mainly risk, on conservation, the distribution risk is the mainly risk, on storage, the volume of the wet rock is the mainly risk.

In this paper we also established a probability model to fast appraisal the exploration risk generally. From the formation we can see that the generation condition is the key factors that influence the formation of the reservoir, the other factors such as the high quality shale, the content of organic, the thermal maturity of the organic, the roof and floor layer condition, the fault condition, the lateral outlet, the depth of buried, the erosion condition all have one condition at least for the value to be zero, means theirs determined influences; the last two factors of the content of the brittle mineral and the volume percentage of the wet rock are the plus term, means that they are the important factors but not the determine factors.

\section{REFERENCES}

[1] Y. X. Li, "The resource potential, development process, exploration prospect of shale gas in China," Abstracts of the 2013 academic annual meeting of the Geological Society of Chinese -theory and technology branch of S13 oil and gas, unconventional energy exploration and development, the Geological Society of Chinese, press, murch, 2013. unpublished.

[2] Y. Yu, "Fuling shale gas commercial wing," Chinese petroleum and petrochemical, vol. 19, 2014, pp. 22-33.

[3] D. F. Hu, H. R. Zhang, K. Ni, et al," Main con-trolling factors for gas preservation conditions of marine shale in southeastern margins of Sichuan basin," Nature Gas Industry, vol. 34, 2014, pp. 17-23.

[4] X. S. Guo, "Rules of two-factor enrichment for marine shale gas in southern China - understanding from the Longmaxi formation shale gas in Sichuan and Its surrounding area," Acta Geologica Sinica, vol. 88, 2014, pp. 1209-1218.

[5] F. J. Jiang, X. Q. Pang, X. C, Ouyang, et al, "The main progress and problems of shale gas study and the potential prediction of shale gas exploration," Earth Science Frontiers, vol. 19, 2012, pp. 198-211.

[6] W. R. Hu and J. W. Bao, "To explore the way of Chinese-style shale gas development," Nature Gas Industry, vol. 33, 2013, pp. 17.

[7] B. L. Pu, S. J. Bao, Y. Wang, et al, "The analysis of the conditions that shale gas to be reservoir - Take the American shale gas basin as example," Petroleum Geology and Engineering, vol. 22, 2008, pp. 33-36+39.

[8] T. L. Guo, H. R. Zhang, "Formation and enrichment mode of Jiaoshiba shale gas field, Sichuan Basin," Petroleum Exploration and Development, vol. 41, 2014, pp. 28-35.

[9] Y. J. Li, H. Liu, L. H. Zhang, et al, "Lower limits of evaluation parameters for the lower Paleozoic Longmaxi shale gas in southern Sichuan province," Science China: Earth Science, vol. 56, 2013, pp. 710-717.

[10] S. Q. Wang, S. Y. Wang, L. Man, et al, “Appraisal method and key parameters for screening shale gas play," Journal of Chengdu University of Technology(Science \& Technology Edition), vol. 40, 2013, pp. 609-620.

[11] Y. X. Li, D. W. Qiao, W. L. Jian, et al, "Gas content of gasbearing shale and its geological evaluation summary," Geological Bulletin of China, vol. 30, 2011, pp. 308-317.

[12] X. J. Li, S. Y. Hu, K. M. Cheng, "Suggestions from the development of fractured shale gas in north America," Petroleum Exploration and Development, vol. 34, 2007, pp. 392-400

[13] X. M. Xiao, Z. G. Song, Y. M. Zhu, et al, "Summary of shale gas research in north American and revelations to shale exploration of Paleozoic strata in China south area," Journal of China Coal Society, vol. 38, 2013, pp. 721-726. 